\title{
Design and Development of Multi tube Heat Exchanger using Fluoropolymer
}

\author{
Dilpreet Kaur Hora* and Nitnaware Pravin T
}

${ }^{\dagger}$ Mechanical Engineering,D.Y.patil college of engineering, Akurdi, Pune,Savitribai Phule Pune University

Accepted 15 June 2016, Available online 20 June 2016, Special Issue-5 (June 2016)

\begin{abstract}
Exchange of heat is the most important processes in engineering science. The heat exchanger a device which is used to transfer the heat between flowing fluid.Contentious flow of the fluid in the tubes of the heat exchanger not only corroded the tube but it also degrade the quality of the fluid like; the changes in its thermal conductivity , mass flow rate, density and viscosity. To overcome this disadvantages the inner tube of the metal is replaced by the fluoropolymer tube which is not only chemical inert but also sustain the non-corrosive nature.The fluoropolymer tubes are extruded from high thermal conductivity PFA polymers which are used to obtain the nano-range of fluorinated layer in order to make steel surface hydrophobic.The biggest property of the PF-HEX units is that every component is made from the same fluoropolymer material. This is significant because the use of dissimilar material can make Parts of unit cycle from hot to cold at different rate. It ensures efficiency and long life.
\end{abstract}

Keywords: Perfuoropolyethers, Fluoropolymers, Thermal efficiency, Hydrofobic, (HEX) Heat Exchanger.

\section{Introduction}

Heat exchanger is used to transfer the heat from one fluid to another fluid.It is based on the calorimetry principle. The fluids which flows in the device are separated by a solid wall to prevent mixing although they may be in direct contact. HEX are used in air conditioning, chemical-plants, refrigeration petrochemical-plants, power-station, petroleum refineries ,natural-gas processing, and sewage treatment.

Heat exchangers are traditionally made up of metal which are subject to corrosion and fouling and with time small corrosive dust and corroded part mix with fluid which degrade the quality of fluid and leads to wastage of fluid or affect the effective utilisation of the fluid. So in order to avoid the corrosion sensitive parts are made up of steel and some alloy which are costly.

The present work is the design and development of fluoropolymer heat exchanger pipe to optimize the fouling occur in the heat-exchanging process in any other traditional heat exchangers. For the optimization of the corrosion there is arrangement of the alloys or some other metals.

To avoid the corrosiveness and corroded parts in the heat exchanger we need to select a material which don't degrade easily and which should not affect the thermal performance of the HEX.
In the fluoropolymer heat exchanger the metallic tube is exchanged with the PFPE (perfuropolyether) tubes to prevent the instrument from corrosion to increase the life of the HEX and the quality of the fluid remain unchanged.

The conductivity of non-metallic tubes in heat exchanger is less then there metallic counterparts .But polymer heat exchanger could offer such a benefits as a design freedom, low thermal expansion ,chemical resistance etc. This project analyses the thermal hydraulic and weight trades off associated with polymer heat exchanger to provide essential background for deciding if and where to allocate resources to more detailed analysis and prototype development.

Three basic types fluropolymer heat exchangers are parallel, counter and cross flow. In the parallel-flow both the fluids entered in the same direction, travel in same and leave the heat exchangers in same direction. In counter-flow heat exchangers the fluids enter the exchanger from opposite ends.In a cross-flow heat exchanger the direction of fluids are perpendicular to each other. The surface area across this heat exchanger is usually calculated by tables.

Another types of fluoropolymer HEX are :

1) Shell and tube HEX

2) Tube and tube HEX

3) Plate HEX

4) Plate and shell HEX

*Corresponding author: Dilpreet Kaur Hora 


\section{5) Adiabatic wheel HEX}

6) Phase change HEX

This project works as a tube and tube HEX .In the tube and tube heat exchanger there is a single tube which is mounted inside the outer shell of tube. The fluid flows as a counter current (BOTT T.R.,1995). In the fluoropolymer heat exchanger there is influence of the interfacial free energy crystal/heat transfer surface on the induction period during the fouling (Forster $M$. BohnetM,1999). After the coatings of the perfuoropolymers on the tubes it become hydrophobic and oleophobic, which not only stopped the corrosion of the tube and fouling (Fabbri p,2007). The effect of the surface free energy on the adhesion of biofouling and crystalline fouling (Zhao Q, Liu Y, Wang C, Wang S. Muller Steinhagen H 2005). The nano-modified surface for fouling mitigation techniques are then applied which lead to the invention of the PF tubeing not on it its coating (Malayeri M.R. 2009).

From the above literature it can be observed that the research done gave the path to use the PF-HEX as the inner tube. The whole research is based to improve the effectiveness and the fouling. The corrosion is also minimized which increased the life of the HEX.

\section{Objective}

1) To study the effect, design and fabrication of Fluoropolymer heat exchanger with closed coil structure

2) To design and fabrication of Test rig for testing of Fluoropolymer heat exchanger.

3) Testing of tube heat exchanger in counter flow configuration to determine

- LMTD

- Capacity ratio

- Effectiveness

The sole objective of the present task is minimize the fouling, cost and maintenance of the HEX .As it is clear that the metal tubes used in any other heat exchangers decayed time by time .On the other hand there is a mixing of the removal of these tubes in the fluid which not only changes the flow of fluid as well as its quality of the fluid.

\section{Operational Features}

The features of the above said heat exchanger are as follows:

- The inner and outer coils are fully drainable.

- For maximum efficiency there is a spiral wound.

- Fluid velocity remain unchanged.

- There are neither crevices nor dead spots.

- Excellent for multi-component.

- Highly resistant to thermal and hydraulic shock. Using of polymer tube in the HEX not only minimize the losses but it also improves the quality of the fluid.

\section{Experimental set-up and procedure}

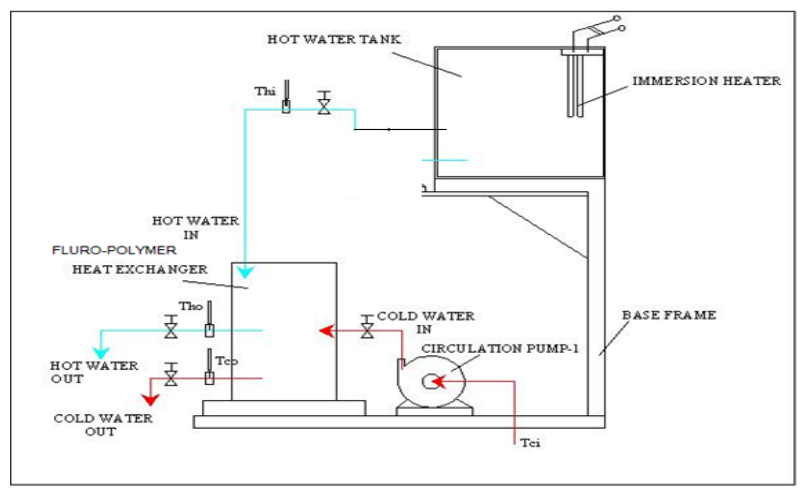

Figure 1: Set -up for fluoropolymer heat exchanger

The system schematic above describes the test rig set up to carry out performance analysis of the u-shape fluoro polymer heat exchanger.

The hot fluid is stored in the hot water tank, water is heated using immersion heat exchanger 300 watt The flow of hot water always takes place in one direction ie top to bottom, by gravity and flow is controlled using a flow control valve. The temperature measurement is done using a j-type thermocouple with single channel digital indicator whereas the flow measurement is done using a measurement beaker with stop watch.

The cold water circuit comprises of submersible pump 30 watt power which circulate water in parallel flow configuration as well as counter flow configuration. The temperature measurement is done using a j-type thermocouple with single channel digital indicator whereas the flow measurement is done using a measurement beaker with stop watch.

Table 1 Specification of the devices used in the HEX

\begin{tabular}{|c|c|c|}
\hline S. No & Parts used & Specification \\
\hline 1 & Tank used & 3.75 lit. \\
\hline 2 & Coil water heater & 350 watt power , temp range $80^{\circ} \mathrm{C}$ \\
\hline 3 & Circulation pump & 30 watt power,250 LPH discharge \\
\hline 4 & Boom & $50 \mathrm{~mm}$ height, $20 \mathrm{~mm}$ breath \\
\hline 5 & Holder pin & With $600 \mathrm{~N} / \mathrm{MM}^{2}$ U.T.S \&380 N/MM $\mathrm{MM}^{2}$ \\
\hline
\end{tabular}

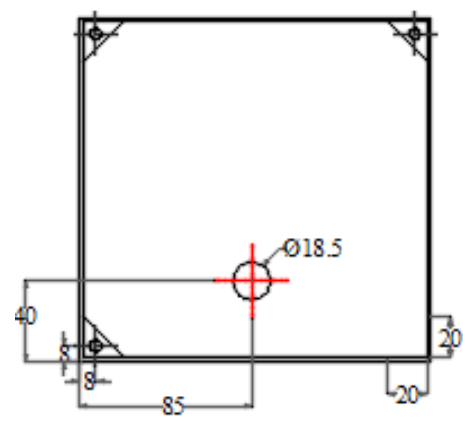

Figure 2: 2-D Drawing of the tank used in the PF-HEX 


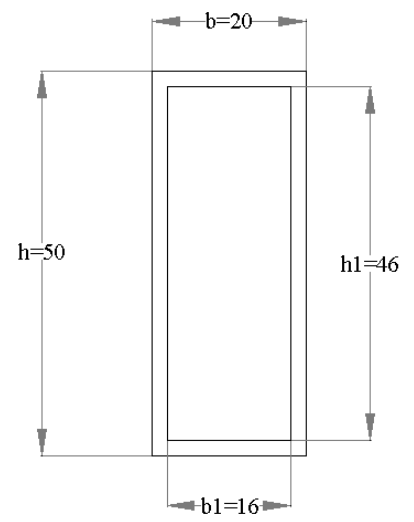

Figure 3: 2-D drawing of the boom used in the PF-HEX

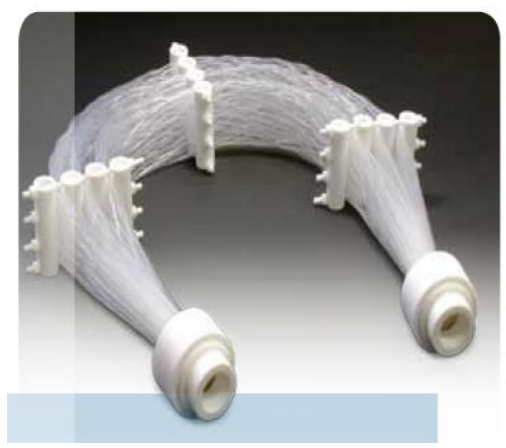

Figure 4: Photograph of U- shaped polymer tube used as inner tube of HEX

This tube is imported from AMETEK fluoropolymer products 455 Corporate Boulevard Newark, Delaware 19702 United States.

This is a leader company in fluoropolymer heat exchanger. The manufactures tubing and pipe from various grades of fluoropolymer resins to meet customer applications.

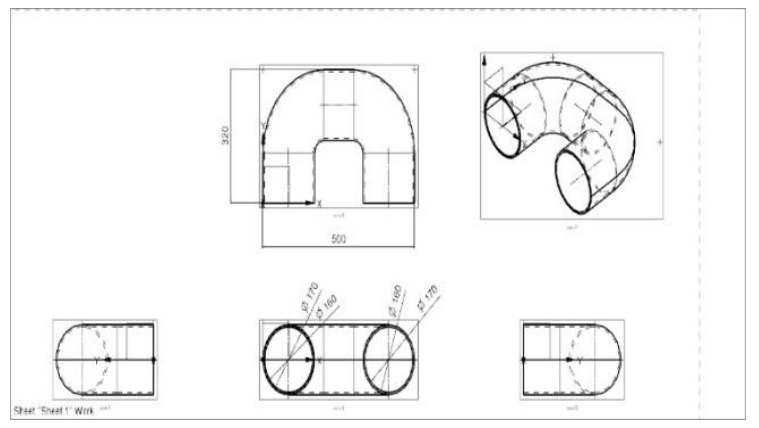

Figure 5: 2-D Drawing of the outer tube of the HEX

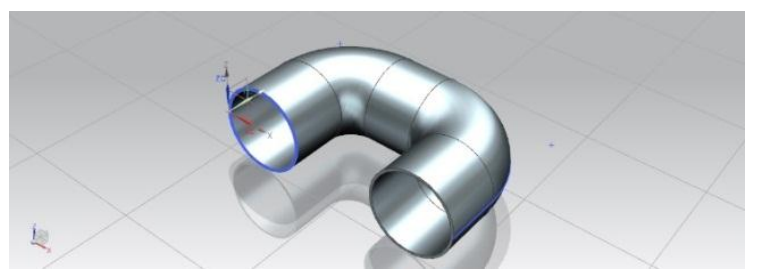

Figure 6: 3-D drawing of the outer tube of HEX

\section{Experimental data and basic calculation}

Table 2 Dimensions of the tubing arrangement

\begin{tabular}{|c|c|c|c|}
\hline S. No & Diameter of inner tube & $\mathrm{D}_{\mathrm{i}}$ & 6.4 \\
\hline 1 & Diameter of outer tube & Do & 12.5 \\
\hline 2 & Length of tube & $\mathrm{L}$ & 2.7 \\
\hline 3 & No. of turns of coil & $\mathrm{N}$ & 7 \\
\hline 4 & Pitch of coil & $\mathrm{P}$ & 30 \\
\hline 5 & Outside diameter of Coil & De & $150 \mathrm{~mm}$ \\
\hline
\end{tabular}

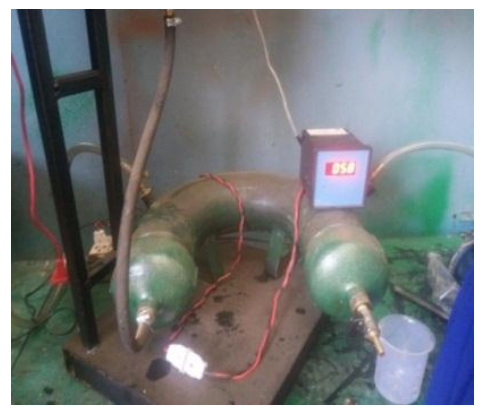

Figure 7: Photograph of fluoropolymer heat exchanger

Table 3 Mass flow of hot water

\begin{tabular}{|c|c|c|c|}
\hline S. No & $\begin{array}{c}\text { Volume in } \\
\text { beaker }\end{array}$ & Time(sec) & $\begin{array}{c}\text { Mass } \\
\text { flow(kg/sec) }\end{array}$ \\
\hline 1 & 200 & 35 & 0.005 \\
\hline 2 & 400 & 76 & 0.0048 \\
\hline 3 & 600 & 114 & 0.0048 \\
\hline 4 & 800 & 156 & 0.0047 \\
\hline 5 & 1000 & 190 & 0.0048 \\
\hline
\end{tabular}

Table 4 Mass flow cold water

\begin{tabular}{|c|c|c|c|}
\hline S. No & $\begin{array}{c}\text { Volume in } \\
\text { beaker }\end{array}$ & Time(sec) & $\begin{array}{c}\text { Mass } \\
\text { flow }(\mathrm{kg} / \mathrm{sec})\end{array}$ \\
\hline 1 & 200 & 18 & 0.01 \\
\hline 2 & 400 & 34 & 0.012 \\
\hline 3 & 600 & 54 & 0.011 \\
\hline 4 & 800 & 76 & 0.010 \\
\hline 5 & 1000 & 93 & 0.010 \\
\hline
\end{tabular}

Table 5 Temperature reading

\begin{tabular}{|c|c|c|c|c|c|}
\hline 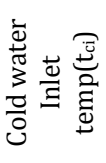 & 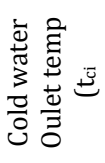 & 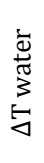 & 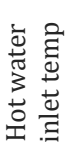 & 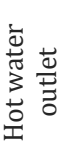 & 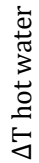 \\
\hline 28 & 36 & 8 & 90 & 53 & 37 \\
\hline \multirow[t]{2}{*}{28} & 38 & 10 & 89 & 51 & 38 \\
\hline & 35 & 7 & 90 & 49 & 41 \\
\hline 28 & 38 & 10 & 88 & 50 & 38 \\
\hline 28 & 39 & 11 & 92 & 52 & 40 \\
\hline
\end{tabular}

\section{6: Mathematical calculations}

$\mathrm{T}_{\mathrm{hi}}=$ Temperature of hot water at inlet $=90^{\circ} \mathrm{C}$

$\mathrm{T}_{\text {he }}=$ Temperature of hot water at outlet $=49^{\circ} \mathrm{C}$ 
$\mathrm{T}_{\mathrm{ci}}=$ Temperature of cold water at inlet $=28^{0} \mathrm{C}$

$\mathrm{T}_{\mathrm{ce}}=$ Temperature of cold water at out let $=35^{0} \mathrm{C}$

1. $\operatorname{LMTD}(\theta \mathrm{m})=(\theta 1-\theta 2) / \ln (\theta 1 / \theta 2)$

Where $\theta 1=$ Thi - Tce $=55^{\circ} \mathrm{C}$

$$
\theta 2=\text { The }-\mathrm{Tci}=21^{0} \mathrm{C}
$$

$$
\operatorname{LMTD}(\theta \mathrm{m})=44.14^{\circ} \mathrm{C}
$$

2. The overall heat transfer coefficient can also be experimentally obtained from the heat duty as follows:

$U=0.33456 /(0.0507) \times 44.14$

$\mathrm{U}=0.149 \mathrm{~W} / \mathrm{m}^{2} \mathrm{k}$

For a counter-flow heat exchanger, the F-correction factor equals 1.0 .

3. Capacity ratio :

$\mathrm{C}=(\mathrm{m} \mathrm{Cp})$ small $/(\mathrm{m} \mathrm{Cp})$ large $=0.077 / 0.33456$

$\mathrm{C}=0.23$

4. Effectiveness $(\varepsilon)$

$\varepsilon=($ Thi - The $) /($ Thi - Tci $)$

$\varepsilon=(90-50) /(90-28)=0.645$

\begin{tabular}{|c|c|c|c|c|c|c|}
\hline$\sum_{\text {i }}^{0}$ & 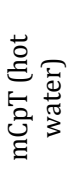 & 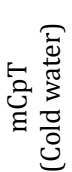 & $\sum_{\unlhd}^{\ominus}$ & $\frac{\substack{N \\
\Xi}}{\vdots}$ & 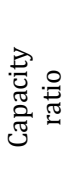 & Effectiveness \\
\hline 1 & $\begin{array}{c}0.31 \\
4\end{array}$ & 0.01 & $\begin{array}{c}37.6 \\
5\end{array}$ & $\begin{array}{c}0 . \\
16 \\
4 \\
\end{array}$ & $\begin{array}{c}0.25 \\
9\end{array}$ & 0.596 \\
\hline 2 & $\begin{array}{c}0.31 \\
0\end{array}$ & $\begin{array}{c}0.01 \\
2\end{array}$ & $\begin{array}{c}35.1 \\
6\end{array}$ & $\begin{array}{c}0 . \\
17 \\
4\end{array}$ & $\begin{array}{c}0.38 \\
6\end{array}$ & 0.622 \\
\hline 3 & $\begin{array}{c}0.33 \\
4\end{array}$ & $\begin{array}{c}0.01 \\
1\end{array}$ & $\begin{array}{c}44.1 \\
4\end{array}$ & $\begin{array}{c}0 . \\
14 \\
9\end{array}$ & $\begin{array}{c}0.23 \\
0\end{array}$ & 0.661 \\
\hline 4 & $\begin{array}{c}0.30 \\
3\end{array}$ & $\begin{array}{c}0.01 \\
0\end{array}$ & $\begin{array}{c}34.1 \\
4\end{array}$ & $\begin{array}{c}0 . \\
17 \\
5 \\
\end{array}$ & $\begin{array}{c}0.34 \\
5\end{array}$ & 0.633 \\
\hline 5 & $\begin{array}{c}0.32 \\
6\end{array}$ & $\begin{array}{c}0.01 \\
0\end{array}$ & $\begin{array}{c}36.1 \\
6\end{array}$ & $\begin{array}{c}0 . \\
17 \\
8\end{array}$ & $\begin{array}{c}0.36 \\
0\end{array}$ & 0.625 \\
\hline
\end{tabular}

Table 6 Result table

\section{Fouling Factor}

Phenomena in which there is a decomposition of the metallic tube due to the deposit of impurities on its surface after the continuous flow of the working fluid. These depositions not only degrade the metallic counterparts but also the effectiveness.

Fouling is occurred by these reasons:

- Low fluid velocity

- Low wall shear stress

- Reaction of the products to the metal

Fouling factor is a function of resistance to flow of fluid due to scaling in the heat exchanger, especially at the hot water side, in case of the u-shape fluoro polymer heat exchanger we shall compare the flow rates at various percentage of valve opening for the flow control valve opening in the condition where the conventional flow will be compared to the flow through the heat exchanger.

Table 7 Fouling factor of u-tube HEX

\begin{tabular}{|c|c|c|c|c|}
\hline S. No & $\begin{array}{c}\text { Percentage } \\
\text { opening of } \\
\text { Valve }\end{array}$ & $\begin{array}{c}\text { Flow rate for } \\
\text { conventional } \\
\text { method w/o } \\
\text { u-polymer }\end{array}$ & $\begin{array}{c}\text { Flow rate for } \\
\text { u-polymer } \\
\text { heat } \\
\text { exchanger }\end{array}$ & Fouling factor \\
\hline 1 & 60 & 0.011588 & 0.011111 & 1.042941176 \\
\hline 2 & 70 & 0.014071 & 0.0125 & 1.125714286 \\
\hline 3 & 80 & 0.015154 & 0.014286 & 1.060769231 \\
\hline 4 & 90 & 0.016417 & 0.016667 & 1.074545455 \\
\hline 5 & 10 & 0.0197 & 0.018182 & 1.0835 \\
\hline
\end{tabular}

\section{Result and discussion}

From the above collected data using polymer tube in HEX it is clear that the whole process of the heat transformation is similar to any other heat exchanger. As these are shock resistance, chemical inert and fully drainable the problem of cavitation and chocking is not occurred. In this way the life and durability of the instrument is increased. On the other hand the quality of the fluid is also remain unchanged. When the LMTD is decreased the overall heat transfer rate is increased, also the effectiveness is increasing. Capacity ratio is increased. The maximum fowling takes place at $70 \%$ valve opening.

\section{Conclusion}

1) By the experiment and the available data we can conclude that the polymer heat exchangers are used in the corrosive environment.

2) These are small volume applications where customized trades off can be made between material properties,thermal performance and cost penalities .

3) Another application is low temperature water heating, where the thermal resistance of the polymer is relatively large part of total and thin wall.

4) Using the polymer HEX the cost is reduced upto 5 and 6 lakh per annum. In this heat exchanger all the operations are as same as in any other 
traditional HEX. But by using the fluoropolymer heat exchanger one may be able to reduce the fouling as well as the corrosion which optimize the cost of the arrangement.

5) In the brief we can say that the industries where there is no need of the heavy amount of heat exchange like swimming pool, medical science, air - conditioning and refrigeration we can use these kind of HEX.

\section{Nomenclature}

$\begin{array}{cl}\text { Symbol } & \text { Discription } \\ \mathrm{U} & \text { Overall heat transfer coefficient } \\ \mathrm{A} & \text { Total surface area of the HEX } \\ \mathrm{T}_{\mathrm{i}} & \text { Inlet temperature of the tube } \\ \mathrm{C} & \text { Capacity ratio } \\ \mathrm{T}_{\mathrm{o}} & \text { Outlet temperature of the tube } \\ \mathrm{T}_{\mathrm{si}} & \text { Inlet temperature of the shell } \\ \mathrm{T}_{\mathrm{so}} & \text { Outlet temperature of the shell } \\ \mathrm{F} & \text { Mass flow rate of the hot fluid } \\ \mathrm{H} & \text { Mass flow rate of the cold fluid } \\ \mathrm{C}_{\mathrm{p}(\text { cold })} & \text { Specific heat of the cold fluid } \\ \mathrm{C}_{\mathrm{p}(\text { hot }} & \text { Specific heat of the hot fluid } \\ \mathrm{T}_{\text {(cold) }} & \text { Temperature of the cold fluid } \\ \mathrm{T}_{\text {(hot) }} & \text { Temperature of the hot fluid } \\ \mathrm{Re} & \text { Reynold no } \\ \mathrm{Nu} & \text { Nusselt no. } \\ \varepsilon & \text { Effectiveness }\end{array}$

\section{References}

Fouling of heat exchanger ISBN 0444821864, Elsevier science and technology book .BOTT T.R.(1995)

Tonelli C., Gavozetti P., Strepparola E (1999), Linear per fluoropolyethers difunctional oligomers: chemistry, properties and application Jouranal of fluoirne chemistry, Vol. 95 pp 51-70.
Forster M. Bohnet. M (1999) Influence of the interfacial free energy crystal/heat transfer surface on the induction period during fouling, International journal of thermal sciences, Vol .38,pp. 944-954

Fabbri p.,(2007) coatings on perfluropolyethers to make it Hydrophobic and oleophobic of the sol-gel method, Advances in polymer technology, Vol. 25 ,No. 3 , pp. 182190.

Zhao Q., Liu Y., Wang C., Wang S. And Muller Steinhagen H (2005) , Effect of surface free energy on the adhesion of biofouling and crystalline fouling, Chemical Engineering Science, Vol. 60 pp 4858-4865.

Costa A.L.H.,(2008) Design optimization of shell and tubes heat exchanger Applied thermal engineering, Vol .28, pp 1798-1805

.Malayeri M.R., A1 Janabi A., Muller Steinhagen H (2009) Application of nano -modified surfaces for fouling mitigation , International Journal of Energy Research,Vol. 33 pp 1103-1113.

Martinelli E., Agostini S., Galli G., Chiellini E ., Glisenti A., Pettit M.E., Callow J.A., Graf K., and Bartels F.W (2008) Nanostructured films of amphiphilic fluorinated block copolymers for fouling release appilication ,Langmuir Vol. 24, pp 13138-13147.

Muller Steinhagen H., Malayeri M.R. and Watkinson P(2011), Heat Exchanger Fouling : Mitigation and cleaning strategies , Heat transfer engineering ,Vol 32(3-4), pp . 189196.

Rosemaninho R., Santos O., Nylander T.,Poulsson M., Beuf M.,Benezech T., Yantsios S., Andristos N., Karabelas A. Rizzo G., Muller Steinhagen H., And Melo L.F (2007) Modified stainless steel surfaces targeted to reduce fouling- Evaluation of fouling by milk components , Journal of food engineering, VOL . 80, PP1176-1187

Zhang H., Lamb R., Lewis J(2005) Engineering nanoscale roughness on hydrophobic surface preliminary assessment of fouling behavior, Science and technology of advanced materials,Vol. 6 pp236-239. 